\title{
sobre infância, experiência e formação docente: um dossiê
}

carmen sanches sampaio ${ }^{1}$ universidade federal do estado do rio de janeiro, brasil josé ricardo santiago ${ }^{2}$ universidade federal do estado do rio de janeiro, brasil tiago ribeiro ${ }^{3}$ universidade federal do estado do rio de janeiro, brasil

O menino ia no mato a onça comeu ele. Depois o caminhão passou por dentro do corpo do menino ele foi contar para a mãe.

A mãe disse: Mas se a onça comeu você, como é que o caminhão passou por dentro do seu corpo?

É que o caminhão só passou renteando meu corpo e eu desviei depressa. Olha, mãe, eu só queria inventar uma poesia.

Eu não preciso de fazer razão.

(Manoel de Barros, 2010, 406)

Eu não preciso de fazer razão - fala a criança de Manoel de Barros. Faz-nos lembrar das metamorfoses do espírito em Nietzsche (2012): i) o camelo, servo e criado da verdade, prisioneiro da obediência e da submissão; ii) o leão, voraz em seu rugido contra o "assim" das coisas e retumbante na afirmação de seu desejo através de um ruidoso "eu quero"; e iii) a criança: afirmação de criação, invenção e transformação fora das economias e dos léxicos da obrigação ou dos valores milenares.

Estas duas imagens da criança - de invenção em Manoel de Barros e criação em Nietsche, ou de criação em Nietzsche e invenção em Manoel de Barros - nos avivam experiências compartilhadas com as crianças, no cotidiano de diferentes escolas públicas. Lembramos, aqui, de uma em especial quando pensávamos e conversávamos, em uma Roda de Filosofia com as crianças, sobre perguntas fáceis ou difíceis. Silêncio, escritas, desenhos, olhares distraídos e interrogativos foram constituindo o tempo desse encontro. A fala de uma das meninas, acompanhada de um gesto de pensamento, presente em seu olhar, nos deslocou de nosso modo

\footnotetext{
${ }^{1}$ E-mail: carmensanches.unirio@gmail.com

2 E-mail: ze_ricardo@hotmail.com

3 E-mail: trsunirio@gmail.com

childhood \& philosophy, rio de janeiro, v. 14, n. 30, maio-ago. 2018, pp. 237-243
}

issn 1984-5987 
(binário e dicotômico) de pensar, ao dizer-nos:

- Porque tem pergunta fácil $e$ difícil de pensar.

Sim, fácil e difícil. O mundo, as questões que nele e dele pululam extrapolam a alternância de um ou. Enredam-se, complexificam-se, tocam umas às outras. Nesse sentido, Pérola, assim como muitas outras crianças, nos ensina algo muito simples e complexo: no processo de aprender e ensinar, quem aprende ensina e quem ensina aprende, independentemente da quantidade de anos ou do tamanho do corpo. Gente grande e gente pequena, gente criança e gente adulta se ensinam. E não estamos nos referindo apenas a conhecimentos estabelecidos como escolares ou didáticos; referimo- nos também aos aprendizados mais difíceis da vida: a escuta, a acolhida, o olhar o outro sem manchá-lo, a conversação, o amor... A possibilidade de ir um pouco além de nós mesmos, de perceber na contrapalavra do outro um convite, uma provocação a enxergar um pouco mais de nossas incoerências e incompletudes.

Como o menino que não precisa "de fazer razão", as crianças nos sinalizam e provocam a perceber que há que inventar nossos modos de existir, ser, estar, fazer. A vida está ao lado da criação; é criação! - lembra-nos a criança nietzschiana. Portanto, receitas, formas cristalizadas, caminhos pré-definidos ou respostas padronizadas podem ser interrogados e abandonados no movimento de existir construindo-se e constituindo- se singularmente e permanentemente no contato com os outros, na relação de alteridade, na experiência... Porque há que inventar e inventar-se: não há formação senão transformação, isto que acontece sem que nos demos conta muito bem, cujo processo tem um quê de inusitado e indecifrável; é acontecimental, enovela e ebule histórias, trajetórias, encontros, existências...

Pensamos que as infâncias afirmam, antes de tudo, uma relação com inícios, de modo que as crianças, na intensidade de suas infâncias, nos interrogam pela sua potência, pela sua fugacidade, o sentido de estarmos no mundo da forma como estamos. Sendo assim, início menos como ponto de partida, e mais como possibilidade de transformação; quiçá ponto de inflexão.

Há que deixar a infância dizer sua própria língua, mostrar-se em sua face, com seu nome, sua impossibilidade de definição, de controle. As crianças são sem 238 childhood \& philosophy, rio de janeiro, v. 14, n. 30, maio-ago. 2018, pp. 237-243 issn 1984-5987 
controle; escapolem, escorregam, dão a pensar, provocam... Trata-se de estar em relação com a infância, na infância, viver seus atravessamentos... Mais do que compreendida, a infância é para ser sentida, vivida, experienciada.

E nós, educadores, como temos nos relacionado com ela? Temos nos permitido aprender com as crianças? O que pode a infância? Como se constituir docente na relação com as infâncias e com as crianças, abrindo-se para uma relação infantil com o seu fazer? Que movimentos este encontro propicia na formação docente? O que pode ser um fazer docente infantil?

Com o desejo de nos interrogar, indagando nossas formas de pensar e estar no mundo, com o desejo de aprender com a pluralidade e, ao mesmo tempo, a singularidade infantil, apresentamos este dossiê, composto por uma polifonia de vozes que buscam escutar a infância em sua potência criadora, inventiva e criativa, em sua força e devir, em sua existência alteritária. Escutar e aprender com ela. Conversar.

Uma dessas vozes, de Carlos Skliar, chega-nos através do primeiro texto, o ensaio infâncias da linguagem, infâncias da infância, memórias de infâncias: depois é tarde demais, no qual o autor pensa poeticamente infância, filosofia e solidão, além de lançar mão de imagens literárias que dizem de uma infância que extrapola a cronologia, o tempo linear. O texto é um convite a buscar olhar com atenção as coisas sem serventia, as palavras quase silentes, os gestos mínimos e talvez perceber, aí, uma poética outra da infância que afirma sua voz.

Sim: afirmar sua voz porque a criança tem voz e nos fala o tempo todo se somos capazes de escutar e/ou compreender. A criança é um outro (MELLO, 2009). A criança é esta existência que nos interpela, silencia, estranha, emudece, inquieta. A criança é um outro da formação, afirmam Tiago Ribeiro, Rafael de Souza e Adrianne Ogêda Guedes, no segundo artigo do dossiê, intitulado infância, alteridade e formação docente: encontro com as crianças como potência de transformação. Compreendendo "a infância como uma força que nos faz devir no tempo, no espaço, na relação", o artigo invita a pensar a "formação com a infância" enquanto uma possibilidade de formação como experiência, isto é, um processo formativo no qual o pensar e o pensar-se com o outro são constitutivos do movimento de 239 childhood \& philosophy, rio de janeiro, v. 14, n. 30, maio-ago. 2018, pp. 237-243 issn 1984-5987 
transformação de si.

Em seguida, em por entre olhares: imagens na educação e possibilidade de um devir-formação de professores, César Donizetti Pereira Leite e Andreia Regina de Oliveira Camargo compartilham aprendizagens e reflexões vivenciadas em duas pesquisas sobre produção de imagens desenvolvidas em duas escolas públicas de educação infantil no interior de São Paulo. A pesquisa tece considerações sobre "experiências formativas" que dão a pensar modos outros de viver e praticar a formação com educadores de educação infantil: "devir-formação".

O quarto artigo, de Camila Machado de Lima, infâncias e formação docente: gestos, sentidos e começos, continua a ensaiar sobre infância e formação docente. Afirma a infância como potência, existência, "vida encarnada em qualquer corpo e em outra temporalidade". A autora se pergunta sobre como nos formamos com a infância e como as infâncias nos formam, a partir de gestos e experiências vivida na prática com crianças de educação infantil em uma escola pública no Rio de Janeiro.

De autoria de Alexandre Simão de Freitas - o círculo mágico e a arte de (não) repetir-se na infância: exercitação e aprendizagem no estágio das sereias - aponta a formação docente como localizada no "centro de uma cadeia histórica de adestramentos que visa o aperfeiçoamento do homem pelo homem através da arte sutil de aumentar o grau de dificuldade para os infantes que chegam". Igualmente, provoca a pensar a infância e o que significa pensá-la em um mundo que faz doer e dói, em sua desigualdade e abandono, explorando contribuições da filosofia do nascimento de Peter Sloterdijk.

No artigo, da necessidade de interrogar o pensamento: gestos sobre a infância no tempo escolar, Luciana Pacheco Marques, Cristiane Elvira de Assis Oliveira e Núbia Schaper Santos, no movimento de pensar a relação entre tempo, infância e experiência, indagam: quais olhares sobre a infância na interface com o tempo escolar têm sido apresentados nas produções em educação? A tensão entre o tempo social e o tempo como intensidade do presente revela a necessidade de gestos pedagógicos que, no pensar esta tensão, considerem as crianças, suas infâncias e relações vividas com a escola, com o conhecimento e com a vida. Escola 240 childhood \& philosophy, rio de janeiro, v. 14, n. 30, maio-ago. 2018, pp. 237-243 issn 1984-5987 
e universidade, nesse processo, inventam caminhos não somente imaginados como possíveis.

Ainda no universo da educação básica, o próximo artigo, de Luciano Bedin da Costa, Joelma de Vargas Borges e Rita de Cássia Azzolin - inspirando mundos: pensar, agir e escrever infâncias em uma escola pública brasileira - apresenta a construção de um pensar-fazer-escrever-com as crianças. E movimentos e fragmentos de um livro organizado por professoras da escola e da universidade, presentes neste artigo, trazem registros, narrativas e escrituras de estudantes acerca das experiências filosóficas vivenciadas. Textos que indiciam uma comunidade filosófica, rastros de infância que se fazem nos cotidianos dessas instituições e de seus coletivos institucionalizados. Textos reveladores da constituição de territórios filosóficos capazes de operar a irrupção do pensar e do escrever-junto.

No oitavo artigo, a infância do professor: currículos vividos no despertar da experiência, Silmara Marton e Allan Rodrigues expressam possibilidades de educar que estão na contramão da velocidade, do pragmatismo e da instrumentalização da razão em prol das respostas prontas, acabadas e aparentemente lógicas. O texto fala de encontros entre jovens e crianças, de disparo de suas sensibilidades. Encontros que dão potência às suas infâncias. Encontros de "Filosofia com Crianças" em uma escola pública e que, por intermédio de dispositivos da Arte e do exercício das faculdades sensíveis, possibilitam, ao grupo envolvido, experimentar uma infância - das crianças e professores - do perguntar-se e da escuta de si e do outro. Proposta educativa provocadora de deslocamentos na perspectiva de uma autoformação mais aberta, sensível a transformações nas próprias formas de ensinar e compreender a formação do professor.

$\mathrm{O}$ artigo de Alexsandro Rodrigues, Castiel Brasileiro, Jésio Zamboni, Marcelo Ferreira e Steferson Roseiro - deslocamentos crianceiros, conversas transviadas: coisas da educação e de afirmação de uma vida que importa - fecha o dossiê e, ao mesmo tempo, abre para questões pouco conversadas na escola, em seus cotidianos: racialidade, gênero e sexualidade. Texto provocativo que nos faz pensar sobre as conversas transviadas na escola, em casa, no trabalho, na vida 241 childhood \& philosophy, rio de janeiro, v. 14, n. 30, maio-ago. 2018, pp. 237-243 issn 1984-5987 
mesma de todo dia, sobre esse "outro perigoso que precisa ser controlado"... Afinal, como lidamos com as crianças e seus modos de ser, estar e pensar que reexistem às impositivas de um modo de existência, definido, demarcado, regulado? O que nos ensinam as crianças que "riem e convidam aos outros com seus rastros de traquinagem"?

As crianças travessas, transviadas, desviantes, "atrasadas", "adiantadas", inquietas... as crianças, suas invenções e sua potência criadora diante de um mundo que lhes é oferecido e que hão de transformar e renovar muito nos ensinam. Suas provocações, gestos, falas, presenças compõem nossos percursos formativos, nossas histórias e trajetórias: há encontros que são pausa na engrenagem de nosso "estar sendo", grão de areia que obsta girarem as rodas do "assim são as coisas", acontecimento que irrompe e desloca.

Os artigos que dão vida e existência a este dossiê infância, experiência e formação docente buscam narrar (des)encontros, aprendizagens e provocações vividas no encontro com estas crianças, estas infâncias. Experiências vividas e compartidas, as quais dão a ver uma pluralidade de modos de pensar, escrever, ensaiar, pesquisar, conversar nutridos pelos e nos encontros entre adultos e crianças e infâncias. Convidam a ouvir e compreender o que as crianças tanto nos dizem cotidianamente, seja através de gestos, silêncios, palavras: há que fazer escola (KOHAN, 2013), há que tecer e criar escola na relação, no contato, nesse espaço que habitamos e inventamos, juntos.

O dossiê é um elogio a uma escola que se (re)inventa na aposta e na ação cotidiana de uma educação-vida eticamente compromissada com a experiência da alteridade, com a singularidade do outro. Uma escola que não se resume ao mesmo, à eterna ratificação do "modelo" construído como neutro e que tem sede de obediência e formatação. Uma escola que tem, sim, partido, qual seja: o pensar e o pensar-se, juntos, o espichar modos de ver, conhecer, experimentar, ler e indagar o mundo: ir mais além de nós mesmos, do que já sabemos, já conhecemos... Experimentar uma conversação na 
diferença, plural. Para que golpes contra a democracia e os Direitos Humanos não sejam celebrados, para que uma execução política, como a de Marielle Franco, não seja motivo de festa, para que não se responsabilizem ou penalizem as crianças faveladas nem suas mochilas pelo tráfico de drogas, como parece fazer a intervenção federal no Rio de Janeiro, para que nenhum governo possa, legitimado pela justiça, aviltar e violentar a universidade pública e seus servidores e estudantes... Para que nenhuma resposta mágica ou verdade cristalizada possa silenciar o pensamento...

Que a leitura deste dossiê possa inquietar e desassossegar pensamentos... Vamos juntos?

\section{referências}

BARROS, M. Poesia Completa. São Paulo: Leya, 2010.

KOHAN, W. O. O mestre inventor: relatos de um viajante educador. Belo Horizonte: Autêntica, 2013.

MELLO, M. B. Lógicas infantis: é a criança um outro? In: LOPES, J. J.; MELLO, M.

B. (orgs.). "O jeito de que nós crianças pensamos sobre determinadas coisas": dialogando com lógicas infantis. Rio de Janeiro: Rovelle, 2009.

NIETZSCHE, F. Assim falou Zaratustra. São Paulo: Martin Claret, 2012. 